Jurusan Fisika FMIPA Univ. Riau Pekanbaru p-ISSN.1412-2960 | e-2579-521X

\title{
PENYERAPAN LOGAM BERAT Pb DAN CU MENGGUNAKAN KARBON AKTIF BERBASIS MAHKOTA NANAS DENGAN VARIASI KONSENTRASI KALIUM HIDROKSIDA
}

\author{
Meylia Susiana Dewi Putri, Awitdrus*, Rita Kartini Manullang \\ Jurusan Fisika Fakultas Matematika dan Ilmu Pengetahuan Alam Universitas Riau \\ *E-mail korespondensi: awitdrus@ lecturer.unri.ac.id
}

\begin{abstract}
This study aims to determine the influence of concentration of potassium hydroxide ( $\mathrm{KOH}$ ) on the adsorption of $\mathrm{Pb}^{2+}$ and $\mathrm{Cu}^{2+}$ metal ions in industrial used water. The activated carbon was prepared from pineapple crown waste. Pineapple crown was pre-carbonized at $180^{\circ} \mathrm{C}$ for 1 hours. Chemical activation was done using $\mathrm{KOH}$ with variations in concentrations of 2, 3, and $4 \mathrm{M}$. The samples were irradiated by using a microwave at 630 Watt of output power for 15 minutes. KOH activation and microwave irradiation power were influenced to the physical properties of the samples. Activated carbon obtained were characterized using SEM, EDX, FTIR and AAS. The results showed that highest adsorption were obtained from activated carbon that was activated by $\mathrm{KOH} 2 \mathrm{M}$. Adsorption efficiency for $\mathrm{Pb}^{2+}$ and $\mathrm{Cu}^{2+}$ metals were $81.15 \%$ and $49.71 \%$, respectively. The carbon chain structure shows the functional groups $C-H, C \equiv C, O-H, C=C$ at wavenumber $2889.49 \mathrm{~cm}^{-1}, 2360.97 \mathrm{~cm}^{-1}, 2339.97 \mathrm{~cm}^{-1}$.
\end{abstract}

Keywords: Pineapple crown, Potassium hydroxide, Microwave irradiation, Activated carbon, Physical properties, Atomic adsorption

\begin{abstract}
ABSTRAK
Penelitian ini bertujuan untuk mengetahui pengaruh konsentrasi kalium hidroksida (KOH) terhadap penyerapan logam berat $\mathrm{Pb}^{2+}$ dan $\mathrm{Cu}^{2+}$ dalam limbah cair industri. Karbon aktif dibuat dari mahkota nanas. Mahkota nanas dipra-karbonisasi pada suhu $180^{\circ} \mathrm{C}$ selama 1 jam. Aktivasi kimia menggunakan $\mathrm{KOH}$ dengan variasi konsentrasi 2 , 3, dan $4 \mathrm{M}$. Sampel diiradiasi menggunakan gelombang mikro dengan daya 630 Watt selama 15 menit. Aktivasi KOH dan iradiasi gelombang mikro berpengaruh terhadap sifat fisis karbon aktif. Karbon aktif yang diperoleh dikarakterisasi menggunakan SEM, EDX, FTIR, dan SSA. Hasil penelitian menunjukkan adsorpsi terbanyak didapatkan dari karbon aktif yang diaktivasi $\mathrm{KOH} 2 \mathrm{M}$. Efisiensi penyerapan untuk logam $\mathrm{Pb}^{2+}$ dan logam $\mathrm{Cu}^{2+}$ masing-masing sebesar $81.15 \%$ dan $49.71 \%$. Struktur rantai karbon aktif memperlihatkan gugus fungsi $\mathrm{C}-\mathrm{H}, \mathrm{C} \equiv \mathrm{C}, \mathrm{O}-\mathrm{H}, \mathrm{C}=\mathrm{C}$ pada bilangan gelombang $2889.49 \mathrm{~cm}^{-1}, 2360.97 \mathrm{~cm}^{-1}, 2339.97 \mathrm{~cm}^{-1}$.
\end{abstract}

Kata kunci: Mahkota nanas, Kalium hidroksida, Iradiasi gelombang mikro, Karbon aktif, Sifat fisis, Penyerapan logam berat.

Diterima 09-02-2020| Disetujui 29-02-2020| Dipublikasi 31-03-2020

\section{PENDAHULUAN}

Dampak yang ditimbulkan dari pencemaran lingkungan semakin meresahkan masyarakat. Salah satu contoh pencemaran lingkungan adalah pembuangan limbah cair industri ke lingkungan tanpa pengolahan terlebih dahulu. Limbah cair industri adalah limbah yang berbahaya karena mengandung bahan pencemar termasuk bahan kimia yang berbahaya dan beracun seperti logam berat kadmium $(\mathrm{Cd})$, timbal $(\mathrm{Pb})$, tembaga $(\mathrm{Cu})$, arsenik (As), raksa (Hg). Logam berat merupakan zat pencemar yang memiliki efek berbahaya karena sifatnya yang stabil dan tidak dapat diuraikan secara biologis [1]. Terdapatnya logam berat pada limbah cair industri dapat menyebabkan kerusakan 
lingkungan dan masalah kesehatan bagi makhluk hidup.

Logam berat dalam limbah cair industri dapat dipisahkan dengan berbagai cara seperti pengendapan kimia, elektrodeposisi, ekstraksi pelarut, ultrafiltrasi, dan penukar ion [2]. Prinsip kerja tersebut mempunyai kekurangan, yaitu menghasilkan lumpur buangan berbahaya dan bisa menghambat kerja pengontrol dan pengeluarannya [3]. Kemudian, kejadian tersebut membutuhkan harga yang besar dan tidak cukup efektif untuk limbah dengan konsentrasi rendah [4].

Adsorpsi merupakan metode yang paling efektif dalam mengurangi logam berat pada limbah cair industri untuk konsentrasi yang rendah. Selain itu, adsorpsi memiliki konsep yang lebih sederhana dan memerlukan biaya yang ekonomis. Proses adsorpsi adalah proses dimana molekul meninggalkan larutan dan menempel pada permukaan zat adsorben [1]. Salah satu material yang dapat dijadikan sebagai adsorben adalah karbon aktif.

Karbon aktif merupakan arang dengan pemprosesan dalam bentuk tertentu yang memiliki kemampuan serapan atau adsorpsi yang besar pada mateial yang berwujud larutan. Karbon aktif memiliki daya serap yang tinggi karena memiliki volume pori yang dapat menyerap gas maupun residu dalam larutan [5]. Karbon aktif dapat dibuat dengan limbah pertanian yang memiliki kandungan selulosa yang tinggi seperti, kulit durian, kulit singkong, ampas tebu, cangkang buah coklat. Karbon aktif diproduksi melalui dua tahap yaitu, pra-karbonisasi dan diikuti dengan aktivasi. Pra-karbonisasi dilakukan untuk mengubah bahan baku menjadi arang yang memiliki pori-pori kecil dan masih tertutupi oleh hidrokarbon dan abu. Aktivasi terbagi atas dua jenis adalah aktivasi fisika dan kimia. Aktivasi fisika dilakukan dengan gas pengoksidasi seperti $\mathrm{N}_{2}$ dan $\mathrm{CO}_{2}$ pada suhu tinggi. Sedangkan, aktivasi kimia dilakukan menggunakan bahan kimia sebagai agen pengaktifan seperti kalium hidroksida $(\mathrm{KOH})$, natrium klorida $(\mathrm{NaCl})$, asam klorida $(\mathrm{HCl})$, seng klorida $\left(\mathrm{ZnCl}_{2}\right)[6]$.
Penelitian ini adalah salah satu cara alternatif untuk mengurangi logam berat yang terdapat pada limbah cair industri kertas dengan memanfaatkan limbah mahkota nanas yang selama ini belum dikelola dengan baik. Tujuan dari penelitian ini yaitu mengetahui konsentrasi aktivasi $\mathrm{KOH}$ yang terbaik pada pembuatan karbon aktif sebagai adsorben pada penyerapan logam berat $\mathrm{Pb}^{2+}$ dan $\mathrm{Cu}^{2+}$.

\section{METODE PENELITIAN}

\section{Pembuatan Karbon Aktif}

Bahan baku utama dalam pembuatan karbon aktif adalah mahkota nanas. Bahan baku diperoleh di Pasar Tradisional Pekanbaru. Mahkota nanas dicuci menggunakan air sebagai penghilang objek yang kotor dan pertikel-pertikel halus yang terletak pada permukaan mahkota nanas. Kemudian, sampel dijemur dibawah sinar matahari selama $2 \times 12$ jam untuk mengurangi kadar air yang terdapat pada mahkota nanas. Sampel dipotong dengan ukuran $\pm 5 \mathrm{~mm}$. Prakarbonisasi dilakukan menggunakan oven listrik selama 1 jam pada suhu $180^{\circ} \mathrm{C}$. Lalu, sampel tersebut dihancurkan menggunakan mortal dan diayak menggunakan ayakan 100 mesh. Tujuan dari pengayakan ini untuk memperoleh ukuran partikel yang homogen. Aktivasi secara kimia menggunakan $\mathrm{KOH}$ dengan konsentrasi 2, 3, dan $4 \mathrm{M}$ yang dicampur menggunakan hot plate dan magnetic stirrer. Kemudian, karbon aktif diiradiasi dengan oven gelombang mikro selama 15 menit dalam 630 Watt. Setelah itu, karbon aktif dinetralkan menggunakan aquades hingga $\mathrm{pH} \sim 7$. Sampel kemudian dipanaskan menggunakan oven listrik dengan suhu $105^{\circ} \mathrm{C}$ selama 9 jam untuk mengeringkan.

\section{Karakterisasi Karbon Aktif dan Penyerapan Logam Berat}

Setelah karbon aktif dihasilkan, kemudian karbon dan karbon aktif dikarakterisasi 
menggunakan spektroskopi transformasi Fourier inframerah (FTIR) untuk mengetahui gugus fungsi yang terdapat pada karbon aktif. Sampel juga dikarakterisasi menggunakan mikroskop pemindaian oleh elektron (SEM) dan energi dispersive oleh sinar-X (EDX) untuk melihat morfologi permukaan dan mengetahui kandungan atom yang terdapat pada karbon aktif.

Pada proses penyerapan logam berat, limbah cair industri diperoleh dari salah satu pabrik industri kertas di Riau. Sebanyak $1 \mathrm{~g}$ karbon dan karbon aktif dicampur dengan larutan limbah cair industri $50 \mathrm{~mL}$ menggunakan hot plate dan magnetic stirrer selama 1 jam. Setelah itu, air disaring menggunakan kertas saring dan dianalisa menggunakan spektrometri serapan atom (SSA). Sampel diberi kode MNOM untuk karbon tanpa aktivasi dan MN2M, MN3M, dan MN4M untuk karbon yang telah diaktivasi dengan konsentrasi masing-masing $2 \mathrm{M}, 3 \mathrm{M}$, dan $4 \mathrm{M}$.

\section{HASIL DAN DISKUSI}

\section{Morfologi Permukaan Karbon Aktif}

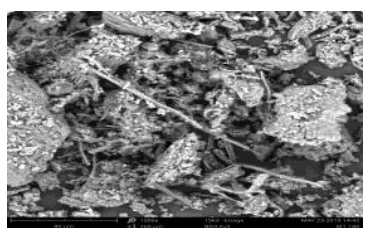

(a)

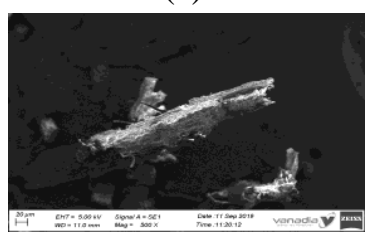

(c)

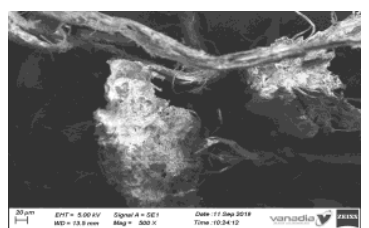

(b)

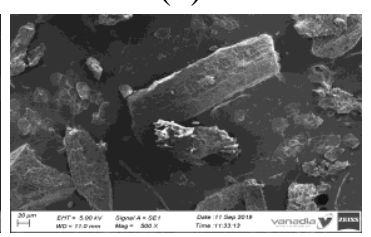

(d)
Gambar 1. Morfologi permukaan karbon aktif (a) MNOM, (b) MN2M, (c) MN3M, dan (d) MN4M.

Morfologi permukaan pada karbon aktif dapat dilihat dengan mikroskop pemindaian oleh elektron. Bentuk permukaan merupakan salah satu faktor yang berperan dalam kemampuan suatu adsorben untuk mengadsorpsi adsorbat. SEM mikrograf ditunjukkan pada Gambar 1.

Gambar 1 (a) memperlihatkan bentuk karbon tanpa aktivasi dimana pori-pori dari karbon masih berukuran kecil dan tertutupi oleh hidrokarbon dan abu. Hal ini menyebabkan daya serap dari karbon tanpa aktivasi masih rendah.

Pada gambar 1 (b), (c), (d) memperlihatkan bentuk karbon aktif setelah diaktivasi memiliki ukuran partikel yang berbeda-beda. Beberapa makropori terbentuk setelah proses aktivasi. Aktivasi yang terjadi terhadap karbon berguna untuk menghancurkan zat-zat pengotor yang terletak pada karbon dan memperbesar poripori karbon sehingga daya serap pada karbon aktif dapat meningkat.

\section{Komponen Karbon Aktif}

Penggunaan energi dispersif oleh sinar-X agar dapat mengamati komponen-komponen yang terdapat pada karbon tanpa aktivasi dan karbon dengan aktivasi. Tabel 1 menunjukkan kandungan yang terdapat pada karbon aktif. Komponen utama pada karbon aktif adalah atom karbon $(\mathrm{C})$ dan oksigen $(\mathrm{O})$. Kandungan karbon yang tinggi menyebabkan oksigen yang terdapat pada karbon aktif menurun.

Tabel 1. Komponen karbon aktif.

\begin{tabular}{lllllll}
\hline \multirow{2}{*}{ Sampel } & \multicolumn{6}{l}{ Persentase Kandungan $(\%)$} \\
\cline { 2 - 7 } & $\mathrm{C}$ & $\mathrm{O}$ & $\mathrm{K}$ & $\mathrm{Mg}$ & $\mathrm{Si}$ & $\mathrm{Sc}$ \\
\hline MN0M & 65.37 & 32.11 & 1.97 & 0.55 & - & - \\
MN2M & 67.53 & 25.42 & - & 1.66 & 0.85 & 4.53 \\
MN3M & 81.83 & 12.82 & - & 0.41 & - & 2.41 \\
MN4M & 71.62 & 22.41 & 3.63 & 1.96 & 0.38 & - \\
\hline
\end{tabular}

Kandungan karbon semakin meningkat setelah proses aktivasi. Hal ini disebabkan oleh terlepasnya zat-zat pengotor yang terdapat pada karbon pada saat proses aktivasi dengan KOH. Dengan meningkatnya kandungan karbon pada sampel dapat meningkatkan daya serap karbon aktif tersebut. Kandungan lain seperti $\mathrm{K}, \mathrm{Mg}, \mathrm{Si}$, dan Sc merupakan kandungan yang terdapat pada bahan baku mahkota nanas. 


\section{Gugus Fungsi Karbon Aktif}

Karbon aktif yang terbuat dari mahkota nanas diuji menggunakan spektroskopi fourier transform inframerah (FTIR) guna mendapatkan gugus fungsi yang terdapat pada karbon aktif menurut puncak serapan yang diperoleh. Bentuk spektra yang diperoleh adalah perolehan serapan vibrasi pada semua konstituen yang terdapat pada sel. Hasil uji FTIR dapat dilihat pada Gambar 2.

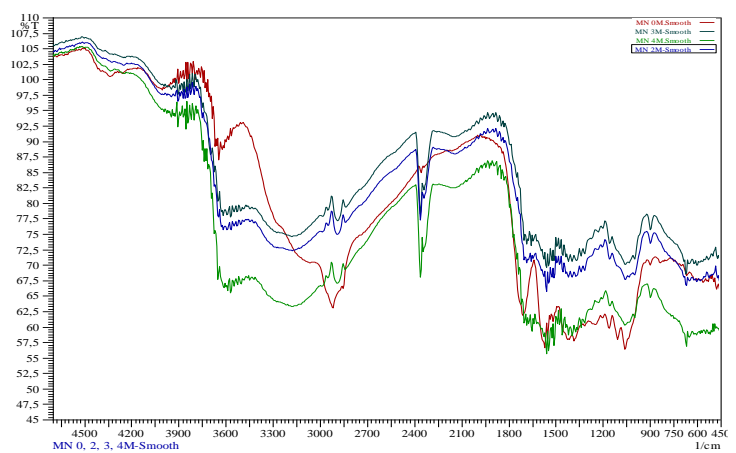

Gambar 2. Spektra FTIR karbon aktif.

Gugus-gugus fungsi yang muncul pada spektra karbon tanpa aktivasi dan yang teraktivasi sama, hanya saja bilangan gelombangnya berbeda. Hal ini disebabkan kejadian aktivasi dan larutan $\mathrm{KOH}$ cukup besar berfungsi agar dapat menghilangkan kotoran yang terdapat pada rongga pori karbon aktif dan membuat pori-pori karbon aktif tersebut terdapat ruang kosong atau terbuka. Daerah serapan $3600-3200 \mathrm{~cm}^{-1}$ yang mengindikasikan adanya gugus fungsi $\mathrm{O}-\mathrm{H}$ [8]. Gugus fungsi $\mathrm{O}-\mathrm{H}$ mengalami pergeseran dan semakin tajam setelah proses aktivasi. Bilangan gelombang $2889.49 \quad \mathrm{~cm}^{-1}$ mengindikasikan terdapatnya vibrasi regangan C-H [9]. Sedangkan, pada bilangan gelombang $2360.97 \mathrm{~cm}^{-1}$ dan $2339.75 \mathrm{~cm}^{-1}$ menunjukkan bahwa karbon memiliki gugus fungsi $\mathrm{C} \equiv \mathrm{C}$ dalam kelompok alkuna. Gugus fungsi $\mathrm{C}=\mathrm{C}$ yang berasal dari cincin aromatik lignin terdapat dalam bilangan gelombang $1587 \mathrm{~cm}^{-1}$. Gugus fungsi dari disebutkan diatas merupakan konstituen dari struktur karbon aktif [10].

\section{Efisiensi Penyerapan Karbon Aktif}

Daya serap karbon aktif diuji menggunakan spektrometer serapan atom (SSA). Konsentrasi awal dari logam berat dalam air limbah dengan konsentrasi akhir setelah ditambahkan karbon aktif, maka akan mendapatkan persentase daya serap pada karbon aktif tersebut. Persentase daya serap dapat diperoleh menggunakan persamaan berikut :

$$
\% \text { adsorpsi }=\frac{c_{0}-c_{1}}{c_{0}} \times 100 \%
$$

dimana $C_{0}$ merupakan konsentrasi awal logam berat (ppm) dan $C_{1}$ merupakan konsentrasi akhir logam berat setelah dicampur dengan karbon aktif.

Terlihat pada Tabel 2 bahwa karbon tanpa aktivasi memiliki efisiensi penyerapan terendah dibanding karbon dengan aktivasi. Hal ini disebabkan oleh karbon tanpa aktivasi memiliki pori-pori yang masih kecil dan juga sebagian porinya masih tertutupi oleh hidrokarbon dan abu. Penyerapan secara maksimum dimiliki pada sampel MN2M yaitu sebesar $81.15 \%$ untuk logam $\mathrm{Pb}$ dan $49.71 \%$ untuk logam $\mathrm{Cu}$. Sedangkan untuk sampel MN4M mengalami penurunan dikarenakan larutan aktivator telah mencapai titik jenuh sehingga tidak sempurna terjadinya aktivasi pada karbon aktif yang kemudian harga efisiensi penyerapan atau adsorpsi mengalami penurunan.

Tabel 2. Efisiensi penyerapan karbon aktif.

\begin{tabular}{lllll}
\hline \multirow{2}{*}{ Sampel } & \multicolumn{2}{l}{$\begin{array}{l}\text { Konsentrasi } \\
\text { Logam } \\
(\mathrm{ppm})\end{array}$} & $\begin{array}{l}\text { Efisiensi } \\
\text { Penyerapan } \\
(\%)\end{array}$ \\
\cline { 2 - 5 } & $\mathrm{Cu}$ & $\mathrm{Pb}$ & $\mathrm{Cu}$ & $\mathrm{Pb}$ \\
\hline Air & 0.171 & 0.244 & - & - \\
Limbah & & & & \\
MN0M & 0.167 & 0.177 & 2.34 & 27.46 \\
MN2M & 0.086 & 0.046 & 49.71 & 81.15 \\
MN4M & 0.159 & 0.126 & 7.02 & 48.36 \\
\hline
\end{tabular}

Konsentrasi $\mathrm{KOH}$ memiliki dampak pada pengosongan rongga pori karbon aktif ketika terjadi aktivasi. Pemberian Konsentrasi $\mathrm{KOH}$ yang tinggi, akan menghasilkan bentuk rongga 
pori yang banyak. Tetapi tingginya konsentrasi $\mathrm{KOH}$ bisa menyebabkan rongga pori karbon aktif yang dihasilkan mengalami kerusakan. Kejadian ini tepat terjadi pada penelitian oleh Santoso (2014) tentang produksi karbon aktif dari kulit singkong dan pemberian aktivator $\mathrm{KOH}$. Karbon aktif yang dihasilkan pada konsentrasi $\mathrm{KOH} 1 \mathrm{M}, 2 \mathrm{M}$, dan $3 \mathrm{M}$ mengalami peningkatan, sedangkan pada konsentrasi $\mathrm{KOH} 4 \mathrm{M}$ dan $5 \mathrm{M}$ mengalami penurunan.

\section{KESIMPULAN}

Dari hasil penelitian dapat disimpulkan bahwa terjadi perubahan bentuk dan pori pada karbon dengan aktivasi. Sampel dengan aktivasi $\mathrm{KOH}$ memiliki kandungan karbon yang lebih tinggi dibandingkan dengan sampel tanpa aktivasi. Efisiensi penyerapan terhadap logam $\mathrm{Pb}^{2+}$ dan $\mathrm{Cu}^{2+}$ yaitu sebesar $81.15 \%$ dan $49.71 \%$. Pada sampel terdapat gugus fungsi $\mathrm{O}-\mathrm{H}, \mathrm{C}-\mathrm{H}, \mathrm{C}=\mathrm{C}$, dan $\mathrm{C} \equiv \mathrm{C}$ yang merupakan gugus fungsi penting dalam karbon aktif. Mahkota nanas dapat dijadikan sebagai bahan baku pembuatan karbon aktif sehingga dapat menyelesaikan masalah lingkungan.

\section{REFERENSI}

1. Misfadhila, S., Zikra, A., Rusdi, \& Cynthia, D. P. C. (2018). Pengaplikasian Cangkang Telur dan Karbon Aktif sebagai Adsorben Logam Timbal. Jurnal Farmasi Higea, 10(2), 126-133.

2. Gadad, G. M. \& White, C. (1989). Removal of Thorium from Simulated Acid Process Streams by Fungal Biomass. Biotechnology and Bioengineering, 33(5), 592-597.
3. Prasad, A. G. D. \& Abdullah, M. A. (2009). Biosorption of $\mathrm{Fe}(\mathrm{II})$ from Aqueous Solution Using Tamarind Bark and Potato Peel Waste: Equilibrium and Kinetics Studies. Journal of Applied Sciences in Environmental Sanitation, 4(3), 273-282.

4. Ashraf, M. A., Maah, M. J., \& Yusoff, I. (2010). Study of Banana Peel (Musa sapientum) as a Cationic Biosorben. American-Eurasian Journal Agricultural and Environmental Science, 8(1), 7-17.

5. Laos, L. E., Masturi, \& Yulianti, I. (2016). Pengaruh Suhu Aktivasi terhadap Daya Serap Karbon Aktif Kulit Kemiri. Seminar Nasional Fisika 2016, Universitas Negeri Jakarta, Geedung Dewi Sartika, DKI Jakarta, 28 Mei 2016, 5.

6. Ioannidou, O., \& Zabaniotou, A. (2007). Agricultural Residues as Precursors for Activated Carbon Production-A Review. Renewable and Sustainable Enegy Review, 11, 1966-2005.

7. Rezaee, A., Rangkooy, H., Jonidi, A., Jafari, A., \& Khavanin, A. (2013). Surface Modification of Bone Char for Removal of Formaldehyde from Air. Journal Applied Surface Science, 286, 235-239.

8. Sahoo, S., Chakraborti, C. K., Behera, P. K., \& Mishra, S. C. (2012). FTIR and Raman Spectroscopic Investigations of a Norfloxacin/Carbopol1934 Polymeric Suspension. Journal of Young Pharmacists, 4(3), 138-145.

9. Fan, M., Dai, D., \& Huang, B. (2012). Fourier Transform Infrared Spectroscopy for Natural Fibers. Fourier TransformMaterial Anlysis, 3, 45-68. 